\begin{tabular}{|c|c|c|}
\hline \multirow{3}{*}{$\begin{array}{r}\text { Case Reports in } \\
\text { Gastroenterology }\end{array}$} & \multirow{2}{*}{\multicolumn{2}{|c|}{ Case Rep Gastroenterol 2017;11:416-421 }} \\
\hline & & \\
\hline & $\begin{array}{l}\text { DOI: 10.1159/000477379 } \\
\text { Published online: July II, } 2017\end{array}$ & $\begin{array}{l}\text { (c) } 2017 \text { The Author(s) } \\
\text { Published by S. Karger AG, Basel } \\
\text { www.karger.com/crg }\end{array}$ \\
\hline & \multicolumn{2}{|c|}{$\begin{array}{l}\text { This article is licensed under the Creative Commons Attribution-NonCommercial } 4.0 \\
\text { International License (CC BY-NC) (http://www.karger.com/Services/OpenAccessLicense). } \\
\text { Usage and distribution for commercial purposes requires written permission. }\end{array}$} \\
\hline
\end{tabular}

\title{
Clinically Silent Intracardiac Metastasis with Extremely Poor Prognosis in a Patient with Hepatocellular Carcinoma
}

\author{
Mashal Salehi The Yee Eric Alatevi Yamin Thein \\ Department of Medicine, NYC Health + Hospitals/Harlem, Columbia University, \\ New York, NY, USA
}

\section{Keywords}

Hepatocellular carcinoma · Intracardiac involvement · Right-sided heart failure ·

Echocardiography $\cdot$ Inferior vena cava

\begin{abstract}
Intracavitary cardiac extension remains an unusual site of extrahepatic metastasis in patients with hepatocellular carcinoma. While patients can present with signs and symptoms suggestive of right-sided heart failure, it may be totally asymptomatic, which is very rare with only a few cases reported so far. Also, cardiac metastasis is of great prognostic importance as patients with intracardiac metastasis can have an extremely poor prognosis. Here, we present the case of a 52-year-old male patient with advanced hepatocellular carcinoma, with an incidentally found tumor thrombus extending from the inferior vena cava to the right atrium, protruding through the tricuspid valve into the right ventricle, on routine echocardiography. The patient did not have any signs or symptoms of heart involvement and unfortunately died on the 18th day of the hospital stay.

(C) 2017 The Author(s)

Published by S. Karger AG, Basel
\end{abstract}




\section{Introduction}

Hepatocellular carcinoma (HCC) is the most common primary malignancy of the liver with most tumors being diagnosed at a late stage. HCC is frequently diagnosed in a liver that is already compromised by chronic disease, most notably by hepatitis B virus or hepatitis $\mathrm{C}$ virus infection [1, 2]. Metastases of HCC to the lung, intraabdominal lymph nodes, adrenal glands, and bone have been well documented as the most common sites for extrahepatic metastases. Intracavitary cardiac extension remains an unusual site of extrahepatic metastasis. Several reports have described cardiac tumor metastases, and their incidence appears to be low in patients with HCC $[3,4]$. The mechanism of tumor spread to the heart can be explained by different mechanisms: direct extension of tumor with thrombus (tumor thrombosis extending along the inferior vena cava to the heart chambers), tumor dislodgment resulting in freely circulating tumor emboli, and direct tumor invasion to the heart [4].

Literature review shows that most reported cases of HCC with cardiac metastasis present with signs and symptoms of cardiac involvement, such as dyspnea, orthopnea, or bilateral lower extremity edema. There are only one or two case reports so far describing patients with clinically silent right-sided heart involvement incidentally found on routine echocardiogram or other imaging modalities.

Here, we present a similar case of a patient with advanced HCC and metastasis to the right side of the heart, yet with no clinical signs or symptoms of heart involvement and extremely poor prognosis.

\section{Case Report}

A 52-year-old Hispanic male patient presented with right upper quadrant abdominal pain and weight loss of 25 pounds in 2 months. On admission, the patient's vital signs showed a blood pressure of 140/95 mm Hg, pulse of $97 \mathrm{bpm}$, respiratory rate of 18 per min, and an oxygen saturation of $94 \%$ on room air. Patient was alert and oriented to time, person, and place, and the rest of the physical examination was significant for icteric sclera and moderately distended abdomen with right upper quadrant tenderness. There was no jugular venous distention, significant cardiac murmurs, or lower extremity edema. Laboratory workup showed deranged liver function tests (AST $413 \mathrm{U} / \mathrm{L}$, ALT $146 \mathrm{U} / \mathrm{L}$, ALP 1,256 U/L, total bilirubin $3.77 \mathrm{mg} / \mathrm{dL}$, direct bilirubin $2.651 \mathrm{mg} / \mathrm{dL}$, albumin $2.7 \mathrm{~g} / \mathrm{dL}$ ), INR of 1.23 , WBC $11 \mathrm{k} / \mu \mathrm{L}$, hemoglobin of $12.9 \mathrm{~g} / \mathrm{dL}$, Hct $39.5 \%$, and platelet count of $233 \mathrm{k} / \mu \mathrm{L}$. Basic metabolic profile showed sodium level $(\mathrm{Na})$ of $140 \mathrm{mmol} / \mathrm{L}$, potassium $(\mathrm{K}) 4.00 \mathrm{mmol} / \mathrm{L}$, bicarb $\left(\mathrm{HCO}_{3}\right) 25 \mathrm{mmol} / \mathrm{L}, \mathrm{BUN} 13 \mathrm{mg} / \mathrm{dL}$, and creatinine level of $0.7 \mathrm{mg} / \mathrm{dL}$. Hepatitis panel was positive for chronic hepatitis B infection. Alpha-fetoprotein was $5,287 \mathrm{mg} / \mathrm{mL}$.

Chest X-ray showed multiple nodules of various sizes in both lung fields without effusion (Fig. 1). Electrocardiogram was unremarkable. Computed tomography of the abdomen and pelvis revealed diffused heterogeneous lesions throughout the liver, moderate ascites, and gallbladder wall thickening. Computed tomography of the chest with contrast showed innumerable bilateral pulmonary nodules consistent with metastasis (Fig. 2).

Magnetic resonance imaging of the abdomen showed multiple heterogeneously T2 hyperintense, centrally necrotic round hepatic masses with internal neovascularity and avid peripheral enhancement. These included a $9.4 \times 11.2 \times 11.2 \mathrm{~cm}$ left hepatic lobe mass with invasion into the middle and left hepatic veins as well as into the inferior vena cava and right atrium. There was also invasion of the left portal vein and distal right portal vein. A $9.0 \times 9.2$ 
$\times 5.3 \mathrm{~cm}$ right hepatic lobe mass centered on segment 7, a $6.8 \times 5.7 \times 6.3 \mathrm{~cm}$ right hepatic lobe mass centered on segment 5 , and a $4.0 \times 3.5 \times 6.7 \mathrm{~cm}$ contour-deforming mass within the anterior left hepatic lobe with foci of internal steatosis consistent with fatty metamorphosis were observed (Fig. 3). Multiple additional smaller masses were scattered throughout the liver. The liver had a nodular, lobulated contour. Magnetic resonance cholangiopancreatography showed multiple centrally necrotic round hepatic masses with internal neovascularity, avid peripheral enhancement, fatty metamorphosis, and invasion of portal veins, hepatic veins, inferior vena cava, and right atrium. Ultrasound of the liver showed portal vein thrombosis.

A routine echocardiography showed a huge homogeneous mass occupying the entire right atrium and prolapsing across the tricuspid valve into the right ventricle, with a normal left and right ventricular systolic function (Fig. 4).

Patient was started on $60 \mathrm{mg}$ of Lovenox every $12 \mathrm{~h}$ because a possibility of superimposed intracardiac tumor thrombus could not be excluded. On day 2 of the hospital stay, patient was found to be hypoxic and was started on $3 \mathrm{~L}$ of $\mathrm{O}_{2}$ per nasal cannula, with subsequent clinical improvement. Pulmonary embolism was ruled out. On day 12 of the hospital stay, patient developed altered mental status, with low blood pressure, tachycardia, tachypnea, and worsening hypoxia. Patient was afebrile, with no signs of heart failure at that time, and the patient's chest X-ray did not show any new infiltrates suggestive of pneumonia or pleural effusion. Patient was intubated; however, unfortunately he died on the 18th day of hospital stay.

\section{Discussion}

HCC is one of the leading causes of cancer deaths throughout the world, and its incidence is on the rise. Although HCC has a strong propensity for vascular invasion and direct intravascular extension, extension of secondary tumor into the cardiac cavity is relatively rare [3]. Advanced HCC is a disease with poor prognosis and a median survival time of 4-7 months [5]. Extrahepatic metastasis of HCC may reach around 18\%, and the most common sites of involvement are the lungs, lymph nodes, adrenal glands, and bones [6]. Intracardiac involvement rarely occurs in patients with $\mathrm{HCC}$, and its frequency was found around $2 \%$ in various case series [7].

The prognosis of HCC with intracardiac metastasis is poor, with a median survival range of 1-4 months [8]. The most common causes of death in patients with HCC with intracardiac involvement are heart failure and sudden death, which account for $25 \%$ of the patients. Cardiac metastases in hepatocellular cancer can be symptomatically quiescent until the later stages. Autopsy series also reported more frequent and diverse vascular involvement, including the portal vein in $26-80 \%$, the hepatic vein in $11-23 \%$, the inferior vena cava in 9$26 \%$, and the right atrium in $2.4-6.3 \%$ of patients with HCC [9].

Advanced-stage HCC has a very poor prognosis, and if there is metastasis to the right side of the heart, the prognosis becomes even worse. Most of the patients with right-sided metastasis will have signs and symptoms of right-sided heart failure, or they could be totally asymptomatic. Irrespective of the symptoms, when right-sided metastasis is present, it makes the prognosis extremely poor.

Our patient did not have any cardiac signs or symptoms despite of significant rightsided heart involvement. Also, this case shows that HCC with cardiac involvement has an 
extremely poor prognosis. The clinicians should be aware of this fact, as it would definitely affect the overall management of the patients.

\section{Statement of Ethics}

This study was performed in accordance with the ethical standards laid down in the 1964 Declaration of Helsinki and its later amendments.

\section{Disclosure Statement}

The authors declare that there is no conflict of interest regarding the publication of this paper.

\section{Funding Sources}

There was no source of financial support in the form of any grants, equipment, or drugs.

\section{References}

1 Parkin DM, Bray F, Ferlay J, Pisani P: Global cancer statistics, 2002. CA Cancer J Clin 2005;55:74-108.

-2 Matsuda T, Marugame T, Kamo K, Katanoda K, Ajiki W, Sobue T: Cancer incidence and incidence rates in Japan in 2003: based on data from 13 population-based cancer registries in the Monitoring of Cancer Incidence in Japan (MCIJ) Project. Jpn J Clin Oncol 2009;39:850-858.

-3 Kato Y, Tanaka N, Kobayashi K, Ikeda T, Hattori N, Nonomura A: Growth of hepatocellular carcinoma into the right atrium: report of five cases. Ann Intern Med 1983;99:472-474, DOI: 10.7326/0003-481999-4-472.

4 Hanfling S: Metastatic cancer to the heart: review of the literature and report of 127 cases. Circulation 1960;22:474-483.

-5 Natsuizaka M, Omura T, Akaike T, Kuwata Y, Yamazaki K, Sato T, Karino Y, Toyota J, Suga T, Asaka M: Clinical features of hepatocellular carcinoma with extrahepatic metastases. J Gastroenterol Hepatol 2005;20:1781-1787.

6 Pawarode A, Voravud N, Sriuranpong V, Kullavanijaya P, Patt YZ: Natural history of untreated primary hepatocellular carcinoma: a retrospective study of 157 patients. Am J Clin Oncol 1998;21:386-391.

-7 Yu K, Liu Y, Wang H, Hu S, Long C: Epidemiological and pathological characteristics of cardiac tumors: a clinical study of 242 cases. Interact Cardiovasc Thorac Surg 2007;6:636-639, DOI: 10.1510/icvts.2007.156554.

-8 Chang JY, Ka WS, Chao TY, Liu TW, Chuang TR, Chen LT: Hepatocellular carcinoma with intra-atrial tumor thrombi. A report of three cases responsive to thalidomide treatment and literature review. Oncology 2004;67:320-326.

-9 Sung AD, et al: Hepatocellular carcinoma with intracavitary cardiac involvement: a case report and review of the literature. Am J Cardiol 2008;102:643-645. 


\section{Case Reports in Gastroenterology

\begin{tabular}{l|l}
\hline Case Rep Gastroenterol 2017;11:416-421 \\
\hline DOI: 10.1159/000477379 & $\begin{array}{l}\text { C 2017 The Author(s). Published by S. Karger AG, Basel } \\
\text { www.karger.com/crg }\end{array}$ \\
\hline
\end{tabular} \\ Salehi et al.: Clinically Silent Intracardiac Metastasis with Extremely Poor Prognosis in a Patient with Hepatocellular Carcinoma}

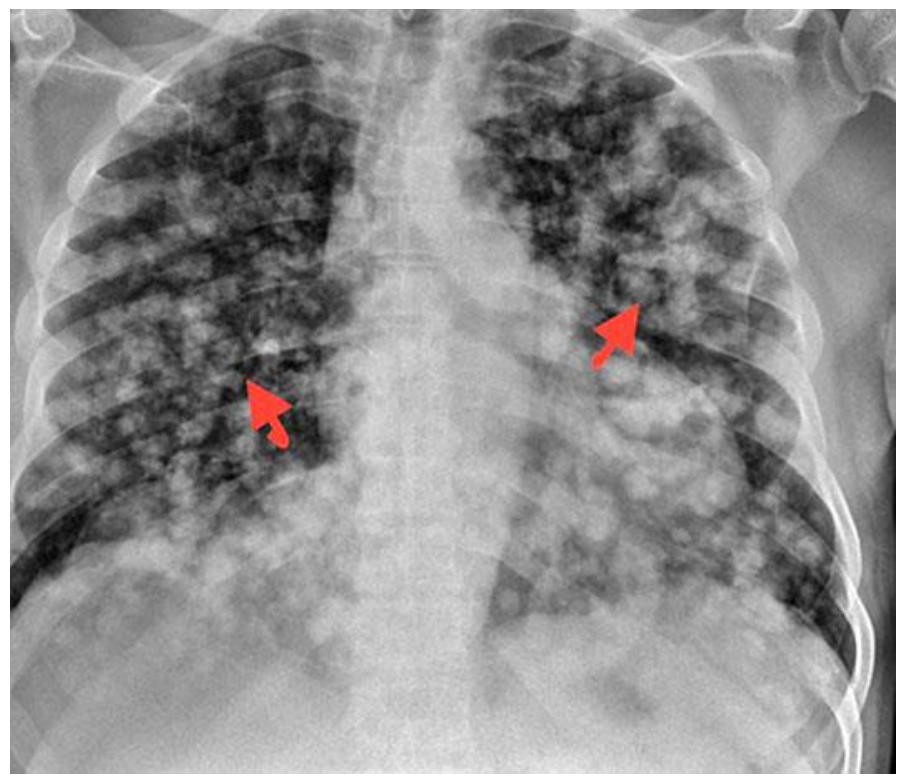

Fig. 1. Chest X-ray showing multiple nodules of various sizes in both lung fields.

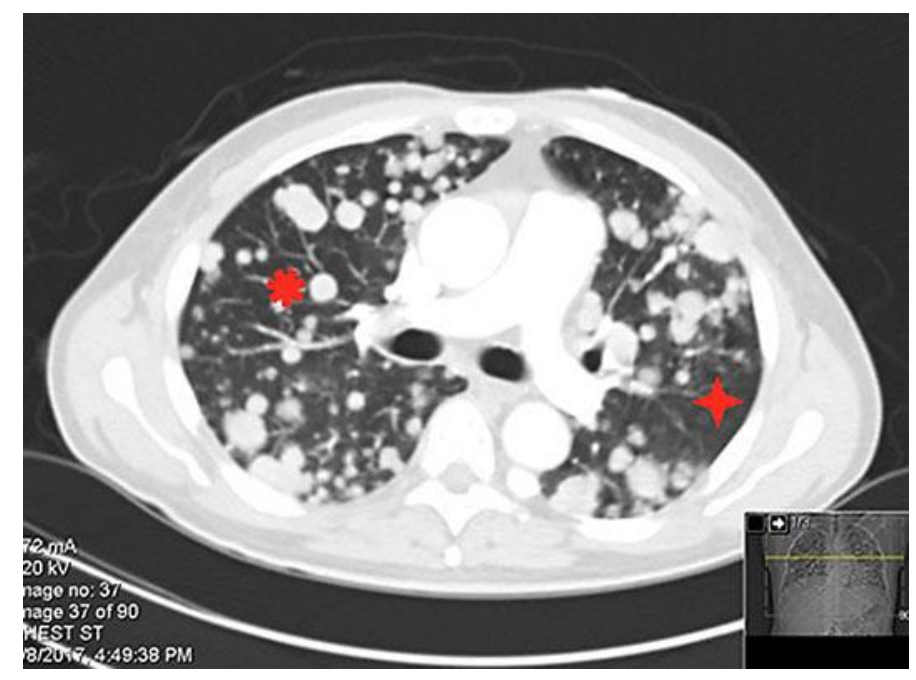

Fig. 2. Computed tomography of the chest with innumerable bilateral pulmonary nodules consistent with metastasis. 

www.karger.com/crg

Salehi et al:: Clinically Silent Intracardiac Metastasis with Extremely Poor Prognosis in a Patient with Hepatocellular Carcinoma

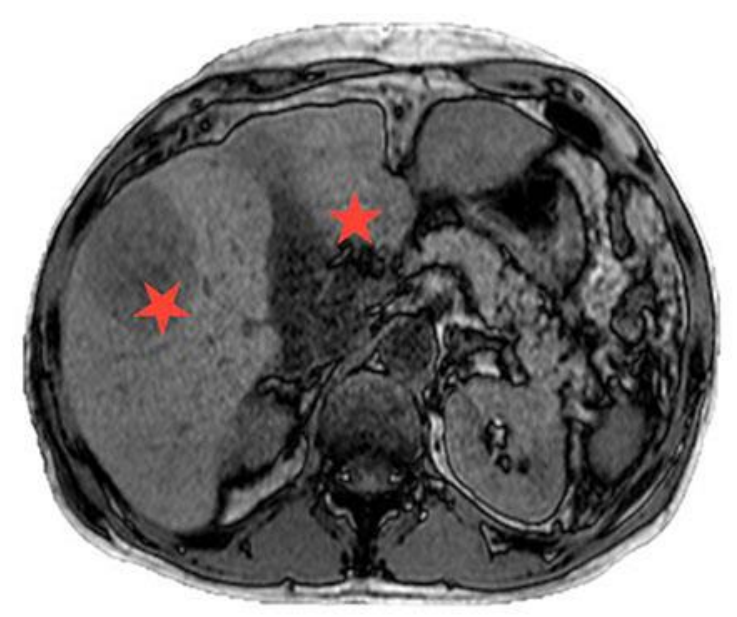

Fig. 3. Magnetic resonance imaging of the liver showing a right hepatic lobe mass and a contour-deforming mass within the anterior left hepatic lobe.

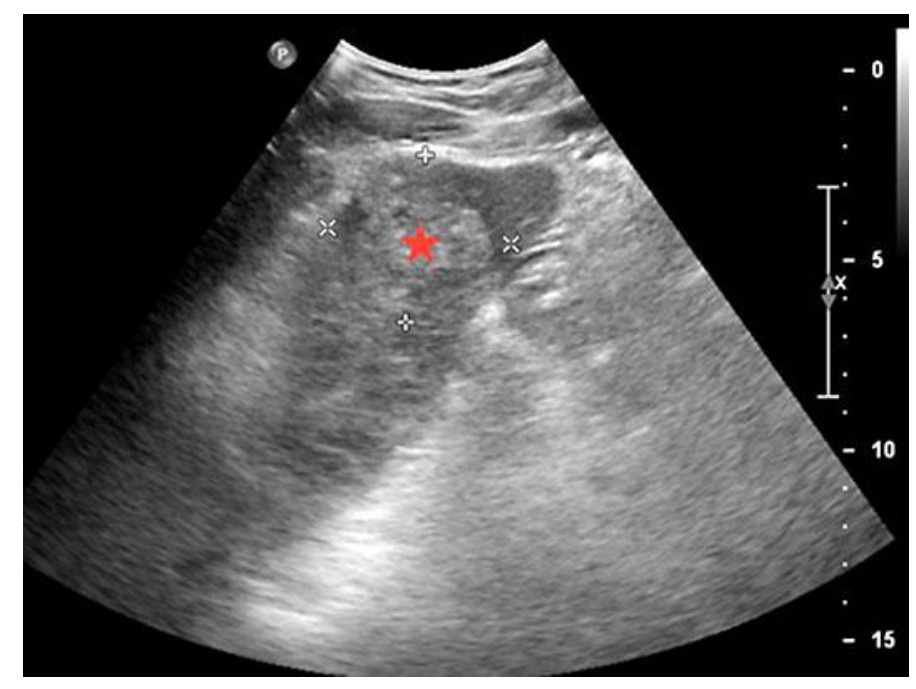

Fig. 4. Echocardiography showing a large right atrial mass. 